\title{
TENDENCIAS GLOBALES DE LA JUSTICIA AMBIENTAL Y EL LITIGIO CONTRA EL CAMBIO CLIMÁTICO
}

\author{
Global Trends on Environmental Justice and Litigation against Climate Change
}

\author{
ISAAC DE PAZ GONZÁLEZ* \\ Universidad Autónoma de Baja California
}

\begin{abstract}
RESUMEN
A medida que los efectos del Antropoceno son cada vez más visibles, ante el foro judicial emergen litigios para proteger el ambiente y aminorar el cambio climático. Los resultados de los juicios y las sentencias son identificables en varias partes del mundo. Su estudio visibiliza las pautas para reivindicar y hacer efectivos los deberes ambientales previstos en acuerdos internacionales y en normas nacionales. En este sentido, el artículo expone que el litigio global está señalando rutas para evitar el deterioro de los ecosistemas y sirve como herramienta complementaria para obligar a los Estados a reducir los efectos del cambio climático.
\end{abstract}

\section{PALABRAS CLAVE}

Cambio climático, litigio, justicia ambiental, casos relevantes

\section{ABSTRACT}

As the effects of the Anthropocene become more and more visible, lawsuits emerge before the judicial forum to protect the environment and reduce climate change. The outcome of such trials and judgments are identifiable in various parts of the world. Its study makes visible the guidelines to claim and make effective the environmental duties provided for international agreements and national legislation. In this sense, the article argues that global litigation is pointing out routes to prevent the deterioration of ecosystems and serves as a complementary tool to bind States to reduce the effects of climate change.

\section{KEYWORDS}

Climate change, litigation, environmental justice, landmark cases

\section{Introducción}

El consumo de combustibles fósiles y el deterioro de los ecosistemas están convirtiendo nuestro planeta en un lugar inhóspito para la continuidad de la vida humana. Desde el 2014, diversos estudios advierten el incremento acelerado del deshielo de los casquetes polares, de las sequías, inundaciones, brotes de plagas, huracanes, e incendios descontrolados que desestabilizan el modo de vida pacífico de las sociedades, e incluso estos fenómenos pueden causar la muerte de miles de personas ${ }^{1}$. El cambio climático y sus intensos efectos se enmarcan en una nueva era denominada Antropoceno, que se define como un período (no necesariamente geológico) ${ }^{2}$ en el que el ser humano impone una dominación total de los

\footnotetext{
* Profesor-Investigador de la Facultad de Derecho-Tijuana de la Universidad Autónoma de Baja California, Campus Tijuana, México. Orcid: https://orcid.org/0000-0002-2267-5629, e-mail: isaac.depaz@uabc.edu.mx. Miembro del S.N.I. (1) y de la Society of Legal Scholars. El autor agradece a los revisores anónimos por sus valiosas y pertinentes observaciones que mejoraron este artículo.

${ }^{1}$ Así lo advierten en sus trabajos KLEIN (2014), pp. 28-29; THORNTON y GOODMAN (2018), p. 269; JARIA-MANZANO (2019), pp. 412413.

${ }^{2}$ Finney y Edwards afirman que inició en 1945, con la explosión de la bomba atómica y la carrera nuclear. También señalan la necesidad de definir los márgenes del Antropoceno como posición política, para reducir sus efectos y como enfoque técnico. FINNEY y EDWARDS (2016), pp. 8-9.
} 
recursos naturales y artificiales que aumentan la emisión de gases de invernadero ${ }^{3}$ (en adelante GEI).

Ante la multiplicidad de factores que provocan el cambio climático, desde la óptica del derecho ambiental y sus normas nacionales e internacionales, se están desarrollando litigios para que los gobiernos materialicen sus compromisos legales y actúen de forma inmediata y directa para evitar el deterioro y la destrucción ambiental. Bajo estas consideraciones, el objetivo de este artículo es ofrecer una panorámica de los resultados del litigio global mediante el análisis de sentencias y juicios (algunos en proceso) que visibilizan, dan forma y demuestran el grado de cumplimiento de las normas y principios del derecho ambiental frente al cambio climático.

El artículo se integra de cuatro partes. En la primera se analiza el marco normativo internacional sobre la protección al medio ambiente y su convergencia con normas nacionales. En la segunda se estudian las principales aportaciones de la Corte Internacional de Justicia (en adelante $\mathrm{CIJ}$ ) que fijaron las bases de la justicia ambiental. En la tercera se analizan los enfoques y rasgos de los casos que han abordado la protección al ambiente en los marcos de justicia regional europea, interamericana y africana. Aclaro que mi estudio solo comprende los mecanismos judiciales, ya que las peticiones que se han planteado sobre el cambio climático y la violación a los derechos ambientales ante la Comisión Interamericana de Derechos Humanos (CIDH) no han prosperado ${ }^{4}$. Las peticiones ante los comités de la ONU se aluden en las conclusiones del trabajo.

En la cuarta parte se analizan resoluciones relevantes en cortes nacionales. Los hallazgos de la investigación muestran que, hasta ahora, las vertientes de los fallos judiciales tienen por objeto: i) obligar a los gobiernos a verificar calidad del aire y reducir la contaminación; ii) obligar a las autoridades a prevenir y evitar la degradación de zonas de importancia biológica; iii) obligar a gobiernos a revertir grandes obras de infraestructura que tienen impacto ambiental negativo; y iv) promover acciones legislativas y del poder ejecutivo hacia entes públicos y privados que afectan el ambiente.

\section{Las normas internacionales y nacionales de protección al ambiente}

La protección amplia del ambiente depende de factores culturales y del modo de producción industrial ${ }^{5}$ que en la actualidad no ha cambiado y que -en consecuencia - no ayuda a detener de una manera eficiente su deterioro global. Sin embargo, ni los defensores ambientales ni los tribunales han permanecido pasivos ante las acciones y omisiones que provocan daños a la naturaleza. Fisher señala que el Derecho está adoptando una perspectiva interdisciplinaria que debe contribuir decisivamente a la creación de decisiones jurídicas y políticas para proteger con mayor fuerza el ambiente ${ }^{6}$. Para Borras, los ámbitos jurisdiccionales refuerzan los compromisos jurídicos y la determinación de responsabilidades sobre el calentamiento global ${ }^{7}$. En efecto, la intervención judicial adquiere relevancia también porque diversos sectores políticos y empresariales rechazan la protección ambiental y la emergencia climática ${ }^{8}$, aunado a que zonas como el círculo polar ártico, el Amazonas y otras regiones cuya biodiversidad contribuye al desarrollo y la continuidad de la vida humana carecen de una protección articulada en niveles políticos, económicos y jurídicos. En este contexto, los

\footnotetext{
${ }^{3}$ Los cambios, riesgos actuales y venideros se analizan en los de trabajos de ELLIS (2018) y ROYNE (2015).

${ }^{4}$ Identifico dos: una petición sobre los efectos del cambio climático sobre el territorio del círculo polar ártico que afecta la vida de los Inuit; "Inuit poeople v. United States", que fue rechazada en el año 2007 por "falta de marco jurídico aplicable"; y la del pueblo "Athabaskan People v. Canáda", pendiente de ser admitida desde 2013. CENTER FOR INTERNATIONAL ENVIRONMENTAL LAW (2013), pp. 3-5.

${ }^{5}$ KLEIN (2015), p. 42.

${ }^{6}$ FISHER et al. (2018), pp. 85 y ss.

7 BORRAS (2013), p. 5.

${ }^{8}$ Sobre la minimización de los riesgos ambientales y el populismo en contra de la emergencia climática véase HILSON (2019), p. 396. 
tribunales han mostrado una preocupación genuina pero insuficiente ${ }^{9}$ para detener el cambio climático. Entre las distintas jurisdicciones que han comenzado a emitir nuevos fallos sobre derechos ambientales ${ }^{10}$ se distingue el objetivo directo la protección a determinadas regiones y ecosistemas, y como prima ratio, preservar la vida de los sectores en situación de mayor vulnerabilidad, como las comunidades indígenas, tribales y otros grupos humanos en condiciones de pobreza. En el sistema interamericano, por ejemplo, se han reivindicado los derechos territoriales y ambientales de los pueblos indígenas porque encarnan el cuidado de la naturaleza compatible con un futuro sustentable ${ }^{11}$.

El litigio ambiental cuenta con objeciones sobre su eficacia. Una de ellas proviene de la protección autónoma del medio ambiente sin vincularla a un daño humano ${ }^{12}$ pero tal objeción carece de fundamento porque en abstracto los servicios ambientales contribuyen de forma integral al desarrollo comunitario y son el nuevo paradigma de la justicia ambiental ${ }^{13}$. Hajjar ha cuestionado la poca efectividad de los fallos y la falta de valoración del medio ambiente frente a los derechos políticos ${ }^{14}$, los cuales tienen plena aceptación y protección en ámbitos procesales, institucionales y económicos. Por otro lado, también se advierten riesgos en las disputas internacionales en las que los litigantes o diplomáticos puedan "vender el medio ambiente" ${ }^{15}$.

Dentro del derecho constitucional destaca la protección articulada en diversas disposiciones para proteger el ambiente. En el sistema mexicano la protección ambiental goza de los principios de progresividad e interdependencia ${ }^{16}$. Las constituciones de Suiza, Bolivia y Ecuador ${ }^{17}$ contienen deberes jurídicos estatales y directrices amplias a favor de la naturaleza ${ }^{18}$; no obstante, en el caso de Ecuador, también hay cuestionamientos sobre el resultado de algunos litigios a favor de la naturaleza por la confusión de la "titularidad de los derechos" y del significado retórico de tal categorización ${ }^{19}$. Otros países han elaborado legislaciones tendientes a reducir los $\mathrm{GEI}^{20}$ y proteger el ambiente. Destacan la Ley de Biodiversidad de Costa Rica ${ }^{21}$, El Plan Nacional de Energía y Clima de Irlanda22, el Código Orgánico del Medio Ambiente de Ecuador $^{23}$, la Ley 12.187 de Brasil del año 2009, y la ley de Dinamarca para reducir el $70 \%$ de sus emisiones de GEI para 203024. En el caso de Chile, por ejemplo, la Ley 20.600 forma parte de un nuevo modelo de justicia ambiental con tribunales y procedimientos especiales que permiten acciones contra proyectos mineros contaminantes.

\footnotetext{
${ }^{9}$ GÓMEZ y LEÓN (2016), p. 237.

${ }^{10}$ Los casos monitoreados, hasta julio, de 2020 arrojan la suma de 1244 en Estados Unidos y 407 en el resto del mundo. SABINE CENTER FOR CLIMATE CHANGE LAW (2020).

${ }^{11}$ Así lo reconoce la Declaración de las Naciones Unidas sobre los derechos de los pueblos indígenas de 2007 y la doctrina actual. Por ejemplo, en el sistema interamericano, ver: DE PAZ (2018), p. 45; sobre las tribus del Pacífico Sur, ver: ROB (2015), pp. 43-54; en el sistema europeo, mediante el principio de prohibición del deterioro de los ecosistemas acuáticos, ver: VAN RISWICK y BACKES (2015), pp. 371-372.

12 HAJJAR (2011), p. 80; SIMON (2013), p. 35.

${ }^{13}$ BELL-JAMES (2019), pp. 292-294. Al que se añade el principio in dubio pro natura como criterio de priorización ante graves riesgos ambientales y que ha tenido un desarrollo jurisprudencial para la reparación del daño ambiental. OLIVARES y LUCERO (2018), pp. 636 y 647.

${ }^{14}$ Incluso se usa el argumento de la falta de recursos para evadir las obligaciones medioambientales. HAJJAR (2011), pp. 90 y 100.

${ }^{15}$ STEPHENS (2009), p. 72.

${ }^{16}$ Según los artículos 1, 2, 4 y 27 de la Constitución de México, que protegen de forma transversal e interdependiente, el derecho a la vivienda, al ambiente, la salud y el acceso al agua potable.

${ }^{17}$ Suiza en su artículo 74; en la Constitución de Ecuador los principios ambientales provienen de los artículos 71, 72, 83.6 y 395; y la Constitución de Bolivia los reconoce en sus artículos 9, 30, 255 (II.7).

${ }^{18}$ A partir de la ampliación normativa, se argumentan ventajas en la especialización de jurisdicciones ambientales en Ecuador y Bolivia. GÓMEZ y LEÓN (2016), pp. 246, 248.

${ }^{19}$ SIMON (2013), pp. 11, 35-37.

${ }^{20}$ Hasta julio de 2020, ver datos en la página del GRANTHAM RESEARCH INSTITUTE ON CLIMATE CHANGE AND THE ENVIRONMENT (2019).

${ }^{21}$ Que en sus artículos 10 y 11 establece la importancia de la participación social; la obligatoriedad del principio de prevención a favor de la naturaleza en consonancia con el Artículo 15 de La Declaración de Rio y el criterio de interés público a favor de la conservación de los ecosistemas y las futuras generaciones.

${ }^{22}$ GOVERNMENT OF IRELAND (2019), preparado en consonancia con la directiva europea 2018/1999 y el Acuerdo de París de 2015.

${ }^{23}$ Destaca el artículo 5 (12) que obliga a "12. La implementación de planes, programas, acciones y medidas de adaptación para aumentar la resiliencia y reducir la vulnerabilidad ambiental, social y económica frente a la variabilidad climática y a los impactos del cambio climático...".

24 DANISH MINISTRY OF CLIMATE, ENERGY AND UTILITIES (2019).
} 
En el ámbito internacional, la exigibilidad de los compromisos ambientales logró mayor atención a partir del Acuerdo de París de 2015, que se firmó con el objetivo de reducir las emisiones de GEl y el aumento de la temperatura global a 1.5 grados. Aunque provocó críticas por tratarse de un documento de buenas intenciones ${ }^{25}$, justo después de 2015 el litigio aumentó y diversos fallos invocan el contenido del Acuerdo de París para que los Estados cumplan los compromisos pactados.

Las directrices ambientales internacionales para la prevención y mitigación del cambio climático tienen sus bases en diversos acuerdos suscritos por los Estados. Por una parte, dichos compromisos constituyen la base de la justicia ambiental ${ }^{26}$ ya que han sido el sustento legal y argumentativo en los litigios ante tribunales nacionales e internacionales. Los más relevantes son: La Declaración de Estocolmo sobre el Medio Ambiente Humano (1972)27; la Convención Marco de las Naciones Unidas sobre el Cambio Climático (1992) derivada de la Cumbre de la Tierra en Rio de Janeiro (1992); el Protocolo de Kyoto de la Convención Marco de las Naciones Unidas sobre el Cambio Climático (1997); El Plan de Acción de Balí; el Acuerdo de Copenhague (2009); el Mecanismo internacional de Varsovia para las pérdidas y los daños relacionados con las repercusiones del cambio climático; los Acuerdos de Paris de 2015; la Conferencia de Bangkok y Conferencia de Katowice (2018) ${ }^{28}$; y la Conferencia de Bonn (2019), que insistió en el cumplimiento del Acuerdo de París.

En Sudamérica, las directrices de la justicia social-ambiental desde la década del noventa proponían mejores esquemas de aprovechamiento comunitario de los ecosistemas, especialmente en la región amazónica ${ }^{29}$ y el instrumento más reciente es "El Acuerdo de Escazú sobre el Acceso a la Información, la Participación Pública y el Acceso a la Justicia en Asuntos Ambientales en América Latina y el Caribe" (2018).

El instrumento internacional que ha tenido más eco en los fallos analizados en este trabajo es la Declaración de Rio mediante sus principios 14, 15, 17 y 22, de los que emanan los principales deberes ambientales: el de prevención a favor de la naturaleza, las obligaciones para evitar la transferencia de actividades nocivas para la salud humana entre Estados, la adopción de medidas eficaces para impedir la degradación del medio ambiente, la creación de mediciones del impacto ambiental, y el rol fundamental de las comunidades indígenas ${ }^{30}$ en la protección del medio ambiente.

Ahora bien, estos deberes ambientales comienzan a tener una adjudicación paulatina en tribunales nacionales, regionales e internacionales, aunque no de manera uniforme $y$ técnicamente con limitaciones, pues la mayoría de dichos tribunales no son expertos en asuntos ambientales ${ }^{31}$. Un logro importante de la articulación judicial de los principios ambientales es la transversalidad del principio de prevención ${ }^{32}$ que además visibiliza la interacción fuerte entre normas $\mathrm{y}$ actores del derecho internacional, regional y nacional ${ }^{33}$ para establecer las responsabilidades y la maximización de sus efectos. De esta manera, los resultados del litigio ambiental buscan incentivar y reivindicar el papel del Estado ante la impunidad y pasividad

\footnotetext{
25 THORNTON y GOODMAN (2018), pp. 255-258. En particular, la más preocupante es la falta de voluntad para su implementación por parte de Estados Unidos, uno de los mayores emisores de gases de efecto invernadero. MILKOREIT (2019), p. 1024.

${ }^{26}$ Véase la evolución y estudios del concepto de justicia ambiental en Estados Unidos en ARNOLD (1998); BULLARD y JOHNSON (2000).

${ }^{27}$ Contiene los 26 primeros principios de preservación y prohibición de las sustancias tóxicas en la tierra.

${ }^{28}$ Que obliga a las Partes contratantes a presentar comunicaciones periódicas, elaboración de planes e informes sobre los avances en la reducción de los gases de efecto invernadero.

${ }^{29}$ GUTIÉRREZ (2014), pp. 123-124.

${ }^{30}$ Este aspecto la jurisprudencia interamericana ha sido pionera sobre reconocimiento de sus tierras e identidad cultural frente a proyectos extractivos desde el caso "Awas Tigni v. Nicaragua"; "Kichwa de Sarayaku v. Ecuador", "Kaliña Lokono v. Surinam"; y en 2020 mediante el caso "Lhaka Honhat v. Argentina”. Ver DE PAZ (2018), pp. 36, 45-50, 63-67.

${ }^{31}$ STEINAR (2016), pp. 73 y ss.

32 Los estándares éticos, jurídicos y hermenéuticos del principio in dubio pro natura son analizados por OLIVARES y LUCERO (2018), pp. 641-647; sobre las relaciones del derecho al agua, la salud y calidad de vida de la población. CARDOSO (2020), pp. 152-153. ${ }^{33}$ El cambio climático requiere acciones de distintas tradiciones legales. En este sentido CARLARNE et al. (2016), pp. 20-44.
} 
administrativa ${ }^{34}$, e inhibir actos $u$ omisiones que provoquen daños ambientales que inciden en el aumento de las temperaturas globales y en el deterioro de la naturaleza.

\section{La Corte Internacional de Justicia y las bases de la justicia ambiental}

Aunque de forma indirecta y limitada ${ }^{35}$, desde sus primeros fallos, la CIJ esbozó los principios de precaución, el deber de cooperación de los Estados en proyectos transfronterizos, y los deberes de la humanidad para evitar daños al ambiente; principios que actualmente se aluden en sentencias regionales y de Cortes nacionales con el objetivo común de evitar la destrucción de los ecosistemas terrestres y marinos.

\section{La planta contaminante Smelter. Estados Unidos v. Canadá (1937)}

En esta controversia arbitral surgieron dos aspectos importantes para el derecho ambiental internacional con un enfoque transfronterizo. En la decisión final, el tribunal arbitral estableció que la compañía canadiense causó daños materiales a propietarios de los poblados fronterizos de Estados Unidos y Canadá (en el aire de la zona, en la producción de leche, lana y otras actividades agrícolas) y estableció dos medidas: que se deberán instalar medidores de sus emisiones contaminantes; y no deberá superarse la emisión de ciertas cantidades de dióxido de azufre porque causa daños a los árboles de la región ${ }^{36}$. La lección de este caso es que los daños transfronterizos identifican agentes particulares que pueden actuar, con aquiescencia del Estado, y generan corresponsabilidad de los daños causados.

\section{Pruebas nucleares. Nueva Zelanda (NZ) v. Francia (1974)}

El tema de ensayos nucleares demostró las ambigüedades y retrasos procesales de la $\mathrm{CIJ}$ cuando se trata de equilibrar las fuerzas hegemónicas en torno al medio ambiente ${ }^{37}$. En el planteamiento de fondo, NZ sostenía que Francia se obligó en el Convenio para la Protección de los Recursos Naturales y el Medio Ambiente de la Región del Pacífico Sur (del 25 de noviembre de 1986) para llevar a cabo una evaluación de impacto ambiental antes de realizar cualquier otro ensayo nuclear en las islas coralinas de Mururoa y Fangataufa. En este aspecto, NZ sostuvo que la conducta de Francia era ilegal ya que causó, o es probable que causara, la introducción de materiales radiactivos al medio marino, por lo que Francia estaba obligada (antes de llevar a cabo sus nuevos ensayos nucleares subterráneos) a proporcionar evidencia de que no darán lugar a la introducción de dicho material en el lecho marítimo. De acuerdo con la petición de NZ, la CIJ emitió una medida de protección provisional en favor de la población neozelandesa de las Islas $\mathrm{Cook}^{38}$. Al momento del dictar el fallo, Francia ya había cesado los ensayos nucleares, por ello la CIJ estableció que el objetivo perseguido por NZ para evitar los ensayos nucleares se había cumplido y no formuló pronunciamiento de fondo.

Opinión Consultiva sobre la Legalidad de las armas nucleares. Asamblea General de la ONU (1996)

En la Opinión Consultiva "Legality of the Threat or Use of Nuclear Weapons", de 1996, la $\mathrm{CIJ}$ reconoce que el ambiente está bajo amenaza diaria y que el uso de armas nucleares podría constituir una catástrofe para el entorno global. La CIJ también reconoce que el medio ambiente

34 BORRAS (2013), pp. 46-47.

35 STEPHENS (2009), pp. 91 y ss.

${ }^{36}$ ONU, Trail Smelter case-United States, Canada (16 de abril 1938 y 11 de marzo de 1941), pp. 1927-1937.

${ }^{37}$ Estos aspectos se advierten en los fallos de los “Australia vs. Francia” y las Medidas Conservatorias (Resolución de 22 de junio de 1973, C.I.J., reportes 1973), p. 105, párrs. 30 y 31 y las medidas conservatorias del asunto en la CIJ, "Ensayos Nueva Zelanda vs. Francia" (1974).

${ }^{38} \mathrm{CIJ}$, “Nueva Zelanda v. Francia” (Orden de medidas de protección, 22 de junio de 1973), párr. 23 y decisión. 
no es una abstracción, sino que representa el espacio vital, la calidad de vida y la misma salud de los seres humanos, incluidas las generaciones por nacer. Asimismo, la CIJ estableció que los principios de protección deben leerse en consonancia con el derecho de defensa de los Estados para evitar la destrucción ambiental ${ }^{39}$. En este mismo sentido, los principios de protección al ser humano se sostuvieron bajo un escenario de riesgo desencadenado por las amenazas de las armas nucleares que, desde Hiroshima y Nagasaki, han significado un quebrantamiento de las obligaciones de respeto al derecho internacional humanitario. El juez Bedjaoui, entonces presidente de la CIJ, mencionó que:

El hombre se está sometiendo a un desarrollo nuclear perverso e incesante chantaje. La pregunta es cómo liberarlo de él. El tribunal esgrimió su deber de desempeñar su papel, aunque sea pequeño, en esta operación de rescate para la humanidad; lo hizo en conciencia y en humildad, teniendo en cuenta los límites impuesta tanto por su Estatuto como por el derecho internacional aplicable ${ }^{40}$.

Aunque la opinión consultiva es ambigua y no establece una prohibición expresa ni vincula jurídicamente a los Estados, en la actualidad constituye un referente de la necesidad para articular mejores soluciones al problema de las armas nucleares como eje para limitar peligros que ponen en riesgo a la humanidad.

\section{Pulp Mills on the River Uruguay. Argentina v. Uruguay (2010)}

Desde el año 2002, surgieron las tensiones entre Argentina y Uruguay por la posible instalación de una planta de celulosa en la frontera que ambos comparten sobre el Río Uruguay. El 4 de mayo de 2006, Argentina presentó un recurso contra Uruguay por presuntas violaciones al Estatuto del Río Uruguay (firmado por ambos Estados el 26 de febrero de 1975). Argentina acusó a Uruguay de haber permitido unilateralmente la edificación de dos plantas de celulosa en el río Uruguay sin respetar los procedimientos obligatorios de notificación previa y consulta acordes al Estatuto aludido ${ }^{41}$. Además, Argentina afirmó que las plantas y sus desechos representaban una amenaza para el río y el ambiente de la zona (así como diversos riesgos para sus pobladores) ya que probablemente perjudicarían la calidad de las aguas y causarían daños al afluente argentino. En el análisis de fondo, la CIJ concluyó que Uruguay había incumplido sus obligaciones fundamentales en virtud del Estatuto de 1975; y con se retomaron las primeras directrices internacionales para fijar el alcance de los daños transfronterizos ${ }^{42}$; aunque también se criticó que la sentencia hizo a un lado el principio de cooperación; el de uso equitativo y razonable de los recursos naturales entre los Estados ${ }^{43}$, y que no aplicó de forma esquemática los principios de la debida diligencia, el precautorio y el de reparación de derechos transindividuales ${ }^{44}$. En efecto, la sentencia no llegó a una conclusión determinante sobre los efectos perniciosos de la planta sobre el ecosistema y la biodiversidad del rio ni sobre la calidad del aire ${ }^{45}$; un hecho que pudiera ser discutible debido a la ausencia de peritajes que no fueron ofrecidos por Argentina sobre esos aspectos. En su voto particular, el juez Antonio A. Cançado Trindade se refirió a la protección del medio ambiente mediante la

prevalencia del elemento de conservación (sobre la simple explotación de los recursos naturales) refleja una manifestación cultural de la integración del ser humano con la naturaleza y el mundo en

\footnotetext{
${ }^{39} \mathrm{CIJ}$, Opinión Consultiva sobre la legalidad de las armas nucleares (8 de Julio de 1996), párrs. 29-32.

${ }^{40} \mathrm{CIJ}$, Opinión Consultiva sobre la legalidad de las armas nucleares (8 de Julio de 1996), Declaration of President Bedjaoui, párr. 6.

${ }^{41}$ En este acuerdo, se habían fijado los procedimientos y las obligaciones de ambos Estados sobre posibles afectaciones al caudal del río.

42 De caso Trail Smelter de 1937, y las derivadas de la resolución sobre la represa del caso "Proyecto Gabcikovo-Nagymaros, "Hungría v Eslovaquia”, CIJ (Sentencia del 25 de septiembre de1997); en el que se obligó a Hungría a indemnizar a Eslovaquia por los daños que causó al abandonar las obras de la represa sobre el rio Danubio.

${ }^{43}$ ANGLÉS (2011), p. 96.

44 LUCERO (2015), p. 74.

${ }^{45} \mathrm{CIJ}$, "Pulp Mills on the River Uruguay. Argentina vs. Uruguay” (Sentencia del 20 de abril de 2010), párrs. 265-266.
} 
el que vive. En mi opinión, tal comprensión se proyecta tanto en el espacio como en el tiempo, como los seres humanos se relacionan, en el espacio, con el sistema natural del cual forman parte y, en el tiempo, con otras generaciones (pasadas y futuras) respecto de las cuales tienen obligaciones ${ }^{46}$.

Bajo esta postura humanista, el voto del juez brasileño también subrayó la exigibilidad de los principios de protección y prevención del daño ambiental de acuerdo a la fuente contaminante o productora del daño, derivado de las obligaciones para proteger los ecosistemas bajo las directrices de la Declaraciones de Estocolmo y de Río e hizo hincapié en la obligación moral y en beneficio de toda la humanidad para tomar las medidas apropiadas que eviten el daño significativo al ambiente como parte esencial de la justicia ambiental ${ }^{47}$.

\section{Caza de ballenas en la Antártica. Australia v. Japón (2014)}

En 1946 las naciones del Pacífico Sur firmaron el Convenio internacional para la regulación de la caza de ballenas y la conservación de los mamíferos y el medio ambiente marino. El caso que presentó Australia ante la CIJ se fundamentó en la actividad ilegal de Japón en otorgar supuestos permisos de investigación científica que en realidad eran para el sacrificio, captura y tratamiento de ballenas. Japón nombró a su programa JARPA II (Japan's research whaling in the Antarctic) y Australia argumentó que los permisos no se otorgaron "para fines de investigación científica" de conformidad con el párrafo 1 del Artículo VIII de la Convención de $1946^{48}$.

Tomando en cuenta la importancia del "Santuario del Pacifico Sur", la CIJ estableció que el programa JARPA II debe revocar cualquier autorización, permiso o licencia existente para matar, capturar o tratar ballenas; y ordenó que

teniendo en cuenta las credenciales ambientales del Gobierno de Japón en varias áreas, instamos encarecidamente a Japón a unirse a la comunidad internacional y cesar toda su investigación científica letal sobre las ballenas, y asegurar el retorno inmediato de los buques que están implementando JARPA $\|^{49}$.

En su opinión separada, el Juez Cançado Trindade expuso un aspecto central sobre el ambiente como derecho y deber de toda la humanidad ya que se trata de un

derecho de cada generación a beneficiarse de este patrimonio natural y cultural, y está inseparablemente unido a la obligación de utilizar este patrimonio de tal manera que pueda transmitirse a las generaciones futuras en condiciones no peores de lo que era [...] y según corresponda, la mejora de la calidad y la diversidad de este patrimonio ${ }^{50}$.

De esta manera, Cançado Trindade señala que la equidad intergeneracional está presente en diversos tratados como un derecho que forma parte de la dignidad humana. Este razonamiento ha tenido eco al menos en las resoluciones de la justicia ambiental de Colombia, como se verá más adelante.

De los asuntos resueltos por la $\mathrm{CIJ}$ es claro que - si bien no se ha dado un contenido concreto a las obligaciones sobre cambio climático, o sobre los principios de precaución y reparación con directrices amplias - las sentencias han servido para fijar pautas para proteger a las poblaciones, al ambiente y a favor de los derechos de las generaciones futuras que se

\footnotetext{
${ }^{46} \mathrm{CIJ}$, “Pulp Mills on the River Uruguay. Argentina vs. Uruguay” (Sentencia de 20 de abril de 2010), párr. 282 (1).

${ }^{47}$ Alude incluso al destino del ser humano y su entorno natural para sobrevivir, de acuerdo con el modus vivendi planteado por Aristoteles. CIJ, "Pulp Mills on the River Uruguay. Argentina vs. Uruguay”, Separate Opinión of Judge Cançado Trindade, (Sentencia de 20 de abril de 2010), ver párrs. 52, 58, 59, 60, 66.

${ }^{48}$ Australia argumentó que la pesca de ballenas solo tenía fines comerciales. Y por ello estableció que la CIJ debía revocar la autorizaciòn dada por el gobierno japones a sus barcos pesqueros. CIJ, "Australia vs. Japón: New Zealand intervening" (Senten cia del 31de marzo de 2014), párr. 25.

${ }^{49} \mathrm{CIJ}$, “Australia vs. Japón: New Zealand intervening” (Sentencia del 31de marzo de 2014), párr. 247.

${ }^{50} \mathrm{CIJ}$, “Australia vs Japón: New Zealand intervening” (Separate Opinion of Judge Cançado Trindade), párr 41.
} 
invocan y están adquiriendo dimensiones concretas en la justicia ambiental ante los tribunales nacionales.

\section{La justicia regional europea, africana e interamericana}

\section{Avances en la justicia ambiental europea}

A partir del año 2005, en la jurisdicción regional europea emergieron casos de justicia ambiental sobre la conservación de sitios de hábitat natural ${ }^{51}$, de prohibición de uso de químicos peligrosos, y sobre el acceso a la información y participación ambiental ${ }^{52}$. También se presentaron asuntos relevantes sobre contaminación del aire, se han resuelto casos sobre el uso nocivo de fertilizantes en España y sobre reducción de gases contaminantes de vehículos en Austria en el Reino Unido ${ }^{53}$. Por otro lado, se ha vertebrado el estudio de las inequidades ambientales por el impacto diferenciado sobre grupos en situación de vulnerabilidad que provoca la falta de acceso a los recursos ambientales ${ }^{54}$.

En el marco de jurisprudencia regional de la Unión Europea (UE), la justicia ambiental mantiene una lógica individualista a través del derecho a la vida privada, pero con cierta restricción en las acciones populares ${ }^{55}$ que buscan proteger el derecho al ambiente a favor de todos. En la cuestión prejudicial C-461/13 se sometieron a consideración de la Corte de Justicia de la Unión Europea (CJUE) las directrices legales, los programas, la política pública y las omisiones para mitigar efectivamente el incremento global de las temperaturas en la región. En su resolución, la CJUE estableció que

los Estados miembros están obligados - sin perjuicio de la posibilidad de que se conceda una excepción - a denegar la autorización de un proyecto concreto si éste puede provocar el deterioro del estado de una masa de agua superficial o si pone en peligro el logro de un buen estado de las aguas superficiales o de un buen potencial ecológico ${ }^{56}$.

La aportación central de la cuestión prejudicial C-461/13 fue la forma de interpretar el principio de protección precautoria ante el peligro de daño a un ecosistema. Esta técnica que ha servido para mejorar la eficiencia de las normas ambientales cuando los jueces la dirigen a operadores de política pública en el sistema regional europeo ${ }^{57}$.

\section{C-565/19 P. Carvalho and Others v. European Parliament and Council} (2019)

En este caso los demandantes - 36 personas y una asociación de jóvenes indígenas de Suecia (Sami) - incoaron ante la CJUE para detener el calentamiento global y reclamaron del Consejo y del Parlamento Europeo el incumplimiento de sus obligaciones positivas para reducir la emisión de GEI en el espacio europeo ${ }^{58}$. También argumentaron que las consecuencias del cambio climático son peligrosas para sus vidas pues - tanto a nivel mundial y regionalrepresentan una amenaza para los medios de vida de cada solicitante, de diferentes maneras en cada caso, pero que provienen de una fuente común: las actividades humanas y la falta de

\footnotetext{
${ }^{51}$ EDWARDS (2006), p. 162. De acuerdo con Pavoni, a partir del año 2005, la jurisdicción regional europea muestra mayor incidencia de casos y tratamiento más propio de justicia ambiental en relación con el derecho a la vida, integridad personal y acceso a la justicia. PAVONI (2013), p. 90.

52 EDWARDS (2006), p. 162.

53 EDWARDS (2006), pp. 166-168.

${ }^{54}$ FILČÁK (2012), p. 4-7.

55 PAVONI (2013), p. 90.

${ }^{56}$ CJUE, C-461/13, Gran Sala (Sentencia del 1 de julio de 2015). Este asunto estableció el alcance de los estándares de protección de las aguas superficiales y los ecosistemas. Sobre este punto, ver VAN RIJSWICK y BACKES (2015), pp. 372 y ss.

${ }^{57}$ Los estándares ambientales se han maximizado gracias a este tipo de interpretación judicial. VAN RIJSWICK y BACKES (2015), p. 377.

${ }^{58}$ CJUE, C-565/19 P (Orden de la CJUE, Segunda Sala, 8 de mayo de 2019), párrs 1-12.
} 
regulación de los gobiernos ${ }^{59}$. En su demanda, los solicitantes plantearon la conexión causal entre las emisiones de GEl, el incremento de las temperaturas y el peligro del cambio climático bajo dos escenarios:

- El escenario RCP (Representative Concentration Pathways) 8.5 asume que ninguna -o casi ninguna- política climática será implementada. Este escenario asume que los países pobres, que actualmente tienen niveles de emisión virtualmente inexistentes, experimentarán desarrollo industrial.

- El segundo el escenario RCP 2.6, por otro lado, asume una situación ideal en la que las reducciones globales comienzan lo antes posible, en las que participan todos los países y cooperan intensamente para asegurar que las reducciones se implementarán ${ }^{60}$.

Los efectos reclamados por los demandantes fueron tanto la actividad positiva de los entes reguladores europeos y la actividad negativa de los particulares que tiene que ver con la prevención de interferencias en los derechos al generar $\mathrm{GEI}^{61}$. Antes de esta petición, la CJUE no tenía una definición clara a favor de la protección de la salud pública ni se había propuesto un litigio sobre los compromisos de todos los Estados en materia ambiental. El 8 de mayo de 2019, el caso se había declarado inadmisible por falta de legitimación activa y en virtud del objetivo que persiguen los demandantes para anular un paquete legislativo aprobado por la Unión y que se adopten nuevas directrices legales para reducir la emisión de GEI y de política pública frente al cambio climático. Lo cual, en opinión de la Segunda Sala de la CJUE es inoperante ${ }^{62}$. Hasta julio de 2020, el asunto se encontraba pendiente de resolver en apelación ante la Gran Sala de la CJUE y en caso de ser procedente sería un hito en la justicia ambiental regional para crear medidas que la emisión de gases contaminante en el bloque europeo.

\section{C-441/17. El Bosque Białowieska. Comisión Europea v. Polonia (2018)}

Este asunto suscitó preocupaciones por la actitud omisiva de Polonia concierne a la protección de una de las reservas vírgenes de Europa: el Bosque Białowieska. El caso reveló que las autoridades polacas talaron al menos 10,000 pinos y abetos que sirven de nidos de al menos 10 especies de aves; limpian el aire y desarrollan un papel esencial como pulmón de Europa del Este. La Gran Sala de la CJUE declaró que Polonia incumplió sus obligaciones de adoptar medidas necesarias para evitar perjuicios en el bosque Bialowieska, por ser un área natural protegida en virtud del artículo 6, apartado 3, de la Directiva relativa a la conservación de los hábitats naturales y de la fauna y flora silvestres ${ }^{63}$. En este sentido y de manera transversal la sentencia ordenó la protección del bosque Białowieska por ser una zona de importancia biológica comunitaria y tener protección legal especial para que no se mate o se perturbe a especies de aves durante su período de reproducción y de crianza y para que no se destruyan, se dañen o se quiten sus nidos de forma intencionada ${ }^{64}$.

\section{C-404/13. ClientEarth v. Reino Unido (2014)}

En el caso C-404/13 se refirió a los altos niveles de emisiones de GEI en el Reino Unido. Previamente, la CJUE había establecido que, cuando los valores límite para el dióxido de nitrógeno se superan después de la fecha límite establecida (que era el año 2011) ${ }^{65}$, y no se ha

\footnotetext{
${ }^{59}$ CJUE, C-565/19 P (Orden de la CJUE, Segunda Sala, 8 de mayo de 2019), párr. 30.

${ }^{60}$ CJUE, C-565/19 P (Orden de la CJUE, Segunda Sala 8 de mayo de 2019), párrs 6,18. Las siglas RCP corresponden a las "Trayectorias de Concentración Representativas" de los GEI.

${ }^{61}$ CJUE, C-565/19 P (Orden de la CJUE Segunda Sala, 8 de mayo de 2019), párrs 5-8.

62 CJUE, C-565/19 P (Orden de la CJUE, Segunda Sala, 8 de mayo de 2019), párrs 65-72.

${ }^{63}$ CJUE, Caso C-441/17 (Sentencia 17 de abril de 2018), párr. 81, 269.

${ }^{64}$ CJUE, Caso C-441/17 (Sentencia 17 de abril de 2018), párr. 83-85, 269.

${ }^{65}$ CJUE, Caso C-404/13 (Sentencia del 19 de noviembre de 2014), párrs. 3, 12, 13.
} 
presentado ninguna solicitud de aplazamiento, los Estados son igualmente requeridos para establecer un plan de calidad del aire con medidas apropiadas para que el período durante el cual se exceden los valores límite se mantenga lo más cortos posible ${ }^{66}$. La CJUE estableció que la sola existencia del plan para mejorar la calidad del aire no corrobora el cumplimiento de las directrices del mismo. A su vez, determinó que cuando un Estado miembro no haya cumplido los valores límite, y no haya solicitado una prórroga del plazo de conformidad con las condiciones prescritas, corresponde a la Cortes nacionales tomar la medida apropiada para que la autoridad establezca el plan requerido ${ }^{67}$. Con esta directriz de la CJUE, las autoridades jurisdiccionales del Reino Unido quedaron en aptitud de ordenar las acciones adecuadas para mejorar la calidad del aire. Esta decisión demostró la necesidad urgente de reorientar la política pública ambiental mediante la directriz judicial cuando las autoridades ejecutivas se nieguen a hacerlo68.

\section{C-57/16. ClientEarth v. Comisión Europea (2018)}

En este caso se toma en cuenta el artículo 11 del Tratado de la Unión Europea, con fundamento en el interés legítimo de una organización para pedir información pública sobre los estudios ambientales y su impacto, la demandante ClientEarth adujo la violación al tratado de la Unión Europea ya que la Comisión Europea negó el acceso a la información de los reportes y proyectos de impacto ambiental en relación con la legislación ambiental europea. De esta manera, ClientEarth estableció que la negativa de información constituye una violación al derecho europeo para acceder a la justicia ambiental ${ }^{69}$.

La CJUE señalo que la información ambiental contiene elementos de interés público que justifican su divulgación para el desarrollo, tanto de políticas públicas como del proceso decisorio, y que ese interés no debe descartarse bajo el argumento de poner en riesgo la toma de decisiones en la Comisión. Por ello, la CJUE determinó que se debe:

anular la decisión [...] de la Comisión Europea por la que se denegó el acceso a un proyecto de informe de evaluación de impacto relativo al acceso a la justicia en materia de medio ambiente a nivel de los Estados miembros en el ámbito de la política medioambiental de la Unión y a un dictamen del comité de evaluación de impacto ${ }^{70}$.

En este asunto prevaleció la idoneidad del interés público para que la información sobre planes de impacto ambiental sea divulgada por los órganos principales de la UE. Como en otros casos, el litigio fortaleció la legitimación procesal para que distintas organizaciones conozcan la información y en su caso accedan a la justicia ambiental.

\section{C-164/1. Tilly-Sabco v. Comisión Europea (2018) y otros}

En el caso C-164/17, la CJUE interpretó una directiva europea sobre la conservación de las aves y sus hábitats. El litigio surgió en los condados de Limerick y Tipperary, (Irlanda) contra la instalación de 16 turbinas para un parque eólico y la ocupación de un territorio montañoso con la extensión de "20935 hectáreas, zonas de turberas, de cobertura sin plantar, matorrales y 12078 hectáreas de bosque"71; que albergan al aguilucho pálido, especie protegida bajo las directivas europeas. Debido al tipo de obras y los trabajos complementarios, el proyecto implicaba la destrucción de bosques y zonas aledañas al hábitat del aguilucho. La CJUE falló en contra de la realización del proyecto porque no garantizaba la protección adecuada al

\footnotetext{
${ }^{66}$ CJUE, Caso C-404/13 (Sentencia del 19 de noviembre de 2014), párr. 23.

${ }^{67}$ CJUE, Caso C-404/13 (Sentencia del 19 de noviembre de 2014), párr. 59 (3).

68 HILSON (2019), pp. 395, 397.

${ }^{69}$ CJUE, C-57/16 (Gran Sala, Sentencia del 4 de septiembre de 2018), párr. 1, 10.

${ }^{70}$ CJUE, C-57/16 (Gran Sala, Sentencia del 4 de septiembre de 2018), párr. 131, Resolutivos (2, 3).

${ }^{71}$ CJUE, C-164/17 (Gran Sala, Sentencia del 25 de julio de 2018), párr. 11.
} 
ecosistema y no tomaba en cuenta el grado de afectación; en este sentido, la CJUE reiteró que el "principio de precaución" aplica en el caso de la Directiva de Conservación de los Hábitats Naturales ya que "permite evitar de manera eficaz cualquier perjuicio que los planes o proyectos previstos puedan causar a la integridad de las zonas protegidas"72.

Como muestra de otros fallos similares contra obras de infraestructura que afectan ecosistemas, la CJUE reitera su posición protectora bajo el principio de precaución cuando se trata de obras que afectan zonas de importancia biológica. Otro caso relevante fue el C-387/15, en el que la CJUE reiteró su jurisprudencia y aludió a la sentencia sobre el plan regional de ordenación territorial para ampliar el Puerto de Amberes (Bélgica) en el margen izquierdo del río Escalda que afectaba la zona protegida denominada Espacio Natura 2000. En dicho litigio, el gobierno belga estableció que "en el momento en que se formuló el proyecto del plan regional de ordenación territorial no existía certeza de que causaría un perjuicio a la integridad de la zona especial de conservación"73.

En este caso de la ampliación del Puerto de Ámberes en Bélgica - bajo el principio de protección amplia y a pesar de la falta de certeza del daño- se estableció con claridad que los prejuicios causados por las obras públicas o privadas no pueden ser omitidos en los requisitos previos para determinar su impacto negativo, porque

el efecto perseguido con las medidas de protección exigidas por el artículo 6 de la Directiva "hábitats" consiste en evitar que, mediante medidas calificadas de "mitigadoras" pero que son en realidad - medidas compensatorias, la autoridad nacional competente eluda los procedimientos específicos establecidos en aquel artículo, autorizando [...] proyectos que causen perjuicio a la integridad del lugar de que se trate ${ }^{74}$.

En ambos casos $C-164 / 17$ y $C-387 / 15$ se pone de manifiesto que la justicia ambiental comienza a extenderse para frenar obras de infraestructura debido a su grado -cierto o incierto- de afectación en zonas con ecosistemas protegidos por las directivas europeas.

En la jurisdicción europea también existen algunos casos contrastantes que muestran la lentitud de la justicia ambiental y la rapidez de los gobiernos para avanzar en la construcción de obras a pesar de los litigios pendientes y de las afectaciones directas de ecosistemas. En el asunto C-142/2016 Alemania negaba categóricamente el impacto significativo por la construcción de una central eléctrica dentro de la zona Natura 2000 en Hamburgo (iniciada en el año 2008). El asunto juzgó que las autoridades administrativas nacionales no buscan alternativas de daños menos gravosos para el ambiente y que no evalúan ni justifican las razones imperiosas - de orden público- para llevar a cabo dichas obras ${ }^{75}$. En la sentencia, la CJUE puso énfasis en la protección de la flora y fauna silvestre en áreas naturales protegidas por las directivas europeas, y estableció que "Alemania transgredió diversas disposiciones ambientales al autorizar la construcción de una central eléctrica de carbón en Hamburgo, sin realizar una evaluación adecuada del impacto que causaría y de las implicaciones en la zona del Rio Elba"76.

\section{Corte Interamericana de Derechos Humanos}

\section{Claude Reyes v. Chile (2006) y Kawas Fernández v. Honduras (2009)}

Las primeras líneas indirectas sobre los derechos ambientales provienen de los casos "Claude Reyes v. Chile" y "Kawas Fernández v. Honduras". En "Claude Reyes" se analizó la violación al artículo 13 de la Convención Americana de Derechos Humanos (CADH) debido a la falta de información que argumentaron varios quejosos al solicitar una evaluación de los

\footnotetext{
72 CJUE, C-164/17 (Gran Sala, Sentencia del 25 de julio de 2018), párrs. 54, 58.

${ }^{73}$ CJUE, C-387/15 y C-388/15 acumulados (Sala Séptima, Sentencia del 21 de julio de 2016), párrs. $11,17$.

${ }^{74}$ CJUE, C-387/15 y C-388/15 acumulados (Sala Séptima, Sentencia del 21 de julio de 2016), párr. 58.

${ }^{75}$ CJUE, C-142/16 (Sentencia del 26 de abril de 2017), párrs. 6, 68-70.

${ }^{76}$ CJUE, C-142/16 (Sentencia del 26 de abril de 2017), párr. 74 (3).
} 
factores comerciales, económicos y sociales de un proyecto de deforestación que se llevaría a cabo en la décimo segunda región de Chile y "podía ser perjudicial para el medio ambiente $e$ impedir el desarrollo sostenible de Chile"77. Entre otros elementos normativos, la Corte IDH mencionó que en 1998 se adoptó la "Convención sobre el acceso a la información, la participación del público en la toma de decisiones y el acceso a la justicia en asuntos ambientales"78 y que todo ello forma parte de la transparencia, la rendición de cuentas y la democracia que debe cumplirse en los Estados Parte ${ }^{79}$. La Corte IDH condenó a Chile por la violación del derecho a un recurso efectivo en materia administrativa ${ }^{80}$. Por otro lado, y como medida de satisfacción se dijo que

el control social que se buscaba con el acceso a la información bajo el control del Estado y el carácter de la información solicitada son motivos suficientes para atender al requerimiento de información, sin que deba exigirse al requirente que acredite una afectación directa o un interés específico ${ }^{81}$.

En su momento, el resultado de "Claude Reyes v. Chile" expuso la importancia de la participación política para proteger el ambiente aunque existen diversas sentencias que indirectamente han abordado la interrelación entre la consulta y la exigibilidad de estudios de impacto ambiental cuando se trata de derechos de los pueblos indígenas y tribales, como consta en los casos "Awas Tigni v. Nicaragua", "Kichwa de Sarayaku v Ecuador", los tres casos contra Paraguay: "Yakye Axa, Sawhoyomaxa y Xàkmok Kàsek"; el de "Kaliña Lokono v. Surinam" y el caso de las comunidades "Kuna y Emberá v. Pánama"82.

Por otro lado, el caso "Kawas Fernández" reveló el grave peligro que enfrentan los defensores medioambientales pues la muerte de Inés Kawas Fernández (y otros ambientalistas) ${ }^{83}$ se dio en el contexto de la lucha por la protección de amplias zonas de reservas naturales. En cuanto al fondo, y por una parte, la Corte IDH reconoció la violación al derecho de integridad personal de la víctima y sus familiares; por la otra, estableció que la defensa del ambiente es parte interdependiente ${ }^{84}$ del derecho a la participación política. En este sentido, la Corte IDH se refirió el reconocimiento de los ambientalistas porque su trabajo "cobra mayor vigencia en los países de la región, en los que se observa un número creciente de denuncias de amenazas, actos de violencia y asesinatos de ambientalistas con motivo de su labor" 85 .

Finalmente, la Corte IDH reconoció la interdependencia de los derechos humanos como parte de su protección integral ya que "la degradación ambiental y los efectos adversos del cambio climático han afectado al goce efectivo de los derechos humanos en el continente" ${ }^{86}$. En suma, y aunque en estos primeros casos, la Corte IDH no se pronunció sobre el cambio climático, si perfiló el alcance axiológico y jurídico en el de las obligaciones ambientales que luego permitirían vertebrar las directrices actuales sobre el medio ambiente en la OC-23/17 y el Caso Lhaka Honhat v. Argentina.

\section{La Opinión Consultiva OC 23/2017}

\footnotetext{
77 Corte IDH, Claude Reyes y otros v. Chile, 19 de septiembre de 2006, párr. 57.13.

${ }^{78}$ Corte IDH, Claude Reyes y otros v. Chile, 19 de septiembre 2006, párr. 84.

${ }^{79}$ Quedó demostrada la importancia de la transparencia informativa cuando se trata de proyectos extractivos y el impacto del litigio bajo estándares de interés público. PAVONI (2013), p. 76

${ }^{80}$ Corte IDH, Claude Reyes y otros v. Chile, 19 de septiembre 2006, párr. 57.13.

${ }^{81}$ Corte IDH, Claude Reyes y otros v. Chile, 19 de septiembre de 2006, párr. 157.

${ }^{82}$ Ver un estudio pormenorizado de los casos citados en DE PAZ (2018), pp. 42-78.

${ }^{83}$ Corte IDH, Kawas Fernández vs. Honduras (3 de abril de 2009), párr. 69. Entre 1996 y 2000 fueron ejecutados al menos cinco ambientalistas más. El móvil aparente fue su oposición a distintos proyectos inmobiliarios y turísticos.

${ }^{84}$ Se afirma que el acceso a la justicia ambiental fortalece la democracia porque empodera a un sector comunitario para proteger su entorno. HAJJAR (2011), pp. 81, 86. Sobre los fundamentos internacionales y estándares de la participación y democracia ambiental, AGUILAR (2020), pp. 81, 84, 93.

${ }^{85}$ Corte IDH, Kawas Fernández vs. Honduras (3 de abril de 2009), párr. 149.

${ }^{86}$ Corte IDH, “Kawas Fernández vs. Honduras (3 de abril de 2009), párr. 148.
} 
En la OC-23/17, y como parte de las medidas progresivas y de una interpretación evolutiva, consciente del cambio climático y de los riesgos que enfrenta en la región, la Corte IDH ha resaltado el interés general y transnacional de protección a favor del ambiente. La Corte IDH partió del fundamento de los principios de prevención y protección ambiental como parte de las directrices amplificadas de los artículos 1 y 2 de la CADH conectados a los tratados ambientales que los Estados americanos han firmado ${ }^{87}$. Estas obligaciones tienen implícito el diseño de mecanismos preventivos y estos abarcan todas las medidas (judiciales y legislativas) para que los derechos no sean violados y para que sean maximizados mediante pautas legales, de política pública y remedios que "aseguren que las eventuales violaciones a los mismos sean efectivamente consideradas y susceptibles de acarrear sanciones $e$ indemnizaciones por sus consecuencias perjudiciales" ${ }^{\prime \prime 8}$.

Como lineamientos del principio de prevención, la OC-23/17 señala que los Estados

tienen la responsabilidad de velar por que las actividades realizadas dentro de su jurisdicción o bajo su control no causen daños al medio ambiente de otros Estados o de zonas que estén fuera de los límites de la jurisdicción nacional. Este principio fue establecido expresamente en las Declaraciones de Estocolmo y de Río sobre el medio ambiente y está vinculado a la obligación de debida diligencia internacional 89 .

Bajo estas directrices, la Corte IDH estableció que "El principio de prevención de daños ambientales forma parte del derecho internacional consuetudinario y [...] no solo abarca la tierra, el agua y la atmosfera, sino que incluye a la flora y la fauna"90. Específicamente en relación con los deberes de los Estados respecto al mar, la Convención de las Naciones Unidas sobre el Derecho del Mar, establece que "[I]os Estados tienen la obligación de proteger y preservar el medio marino", e impone obligaciones de prevenir, reducir y controlar la contaminación del medio marino a manera de política principal.

Las directrices más relevantes de la OC-23717, la Corte IDH señaló las siguientes: 1) el ámbito de aplicación de la obligación de prevención; 2) qué tipo de daño se debe prevenir, y 3) las medidas que deben adoptar los Estados para cumplir con esta obligación ${ }^{91}$. Sobre el tipo el ámbito, se deben contemplar de manera amplia todos los tratados sobre el ambiente terrestre y marítimo; con relación al tipo de daño que se debe prevenir, la Corte IDH, aplica el Artículo 29 (d) de la CADH para abarcar diversos tratados y recurre a la interpretación de la $\mathrm{CIJ}$, que "ha señalado que la obligación de prevención surge cuando hay riesgo de un daño significativo [...] tomando en cuenta la naturaleza y magnitud del proyecto y el contexto donde será llevado a $c^{c a b o "}{ }^{\prime 92}$. Además, de acuerdo a cada caso concreto de los proyectos de infraestructura u otras actividades, y a sus circunstancias particulares, la Corte IDH concluye que

[Los] Estados deben tomar medidas para prevenir el daño significativo al medio ambiente, dentro o fuera de su territorio. Para esta Corte, cualquier daño al medio ambiente que pueda conllevar una violación de los derechos a la vida o a la integridad personal, conforme al contenido y alcance de dichos derechos que fue definido previamente debe ser considerado como un daño significativo ${ }^{93}$.

En cuanto a las medidas para dar cumplimiento a las obligaciones, la Corte estableció que los estados deben llevar a cabo de forma transversal la regulación del tipo de actividades, bajo una supervisión adecuada con mecanismos de fiscalización, requerimiento de estudios de

\footnotetext{
${ }^{87}$ Por ejemplo, los Convenio de Cartagena, el Convenio para la Protección del Medio Marino y la Zona Costera del Pacífico Sudeste (Convenio de Lima); la Convención para la Protección de los Recursos Naturales y el Medio Ambiente de la Región del Pacífico Sur (Convención Noumea), y otros. Corte IDH OC-23/17, 15 de noviembre de 2017, párrs. 84 y 85.

${ }^{88}$ Corte IDH, OC-23/17, 15 de noviembre de 2017, párr. 118.

${ }^{89}$ Corte IDH, OC-23/17, 15 de noviembre de 2017, párr.127

${ }^{90}$ Corte IDH, OC 23/17, 15 de noviembre de 2017, párrs. 247-248.

${ }^{91}$ Corte IDH, OC 23/17, 15 de noviembre de 2017, párr. 130.

${ }^{92}$ Alude el asunto de la planta de celulosa: Argentina v. Uruguay. Corte IDH, Opinión Consultiva "OC 23/17", 15 de noviembre de 2017, párrs. 134-135.

${ }^{93}$ Corte IDH, “OC 23/17", 15 de noviembre de 2017, párrs. 134-135.
} 
impacto ambiental; con la debida participación ciudadana y en su caso de pueblos indígenas; y también se precisa la creación de planes de contingencia y mitigación por los posibles daños ambientales ${ }^{94}$. Un gran logro de sistematización e interpretación interamericana de la OC-23/17 es que ensancha el efecto vinculante de cada tratado sobre ambiente terrestre o marítimo y lo conecta directamente con las obligaciones generales de los Estados parte previstas en la CADH.

\section{El Caso Lhaka Honhat v. Argentina (2020)}

El caso Lhaka Honhat $v$. Argentina representa una nueva era de la justicia ambiental interamericana como parte de su emergente modelo de justiciabilidad de los derechos socioeconómicos sustentado en el derecho internacional de los derechos humanos. El avance de la sentencia Lhaka Honhat es que por primera vez se reconoce el nexo causal entre la transgresión a los derechos de las comunidades y las diversas obras invasivas tanto del Estado y como de las actividades extractivas de particulares que provocaron degradación ambiental. Sobre la degradación ambiental, la Corte IDH retoma sus directrices de la OC-23/17, el marco nacional e internacional (suscrito por Argentina) sobre la prevención del daño ambiental y que le obligaban evitar la intensificación de la vulnerabilidad de las comunidades indígenas ${ }^{95}$.

Por otra parte, el caso Lhaka Honhat revela tres parámetros de justicia ambiental fundamentales para los derechos de los pueblos indígenas: el primero es la adjudicación y análisis interdependiente de los derechos individuales y colectivos de las 132 comunidades: alimentación, identidad cultural y el derecho a la participación en el uso de sus recursos territoriales y en la necesaria protección amplia de su derecho a la propiedad. El segundo proviene de la relación causa-efecto entre las actividades lesivas de particulares (tala, cercos y explotación ganadera) y las omisiones de protección del Estado que afectaron los derechos comunitarios en su conjunto, ya que de su respeto integral dependen la subsistencia y la supervivencia de las comunidades ${ }^{96}$. El tercer parámetro son las medidas de reparación mediante planes de acción ordenados por la Corte IDH para la conservación, recuperación y mejora de los recursos ambientales, el acceso al agua y a la alimentación adecuada en favor de las comunidades ${ }^{97}$. Así, el caso Lhaka Honhat es un hito porque contiene todos los aspectos sustantivos contemplados por el marco jurídico interamericano e internacional ambiental y porque constituye un drástico cambio jurisprudencial a manera de ruta a seguir por los tribunales de los Estados Partes de la CADH para que amplifiquen sus lineamientos de reparaciones integrales cuando confluyan actos públicos y de particulares que degraden el ambiente y los derechos comunitarios.

\section{Casos emergentes en África}

En la jurisdicción supranacional africana hay pocos casos resueltos sobre justicia ambiental. Uno de ellos ha sido Serap v. Nigeria, mediante el cual la asociación civil de pobladores aledaños al Rio Níger reclamo a Nigeria su falta de protección y sanción de la contaminación de la Delta del Rio Níger producida por el vertedero de sustancias tóxicas y restos de la producción industrial de Shell Petroleum en la región. La Corte de Justicia de los Estados Africanos del Este reconoció que Nigeria estaba obligado bajo el Artículo 24 de la Carta Africana de Derechos Humanos y de los Pueblos, a respetar la calidad del ambiente en relación con los seres humanos que viven en el área ${ }^{98}$. En este asunto no se tocó el principio de precaución, pero se visibilizaron los deberes ambientales de Nigeria.

\footnotetext{
${ }^{94}$ Corte IDH, “OC 23/17”, 15 de noviembre de 2017, ver párrs. 141-180.

${ }^{95}$ Corte IDH, Comunidades Lhaka Honhat v. Argentina, sentencia del 04 de febrero de 2020, ver párrs. 207-209.

${ }^{96}$ Corte IDH, Comunidades Lhaka Honhat v. Argentina, sentencia del 04 de febrero de 2020, ver párrs. 243-253, 284, 287289.

${ }^{97}$ Corte IDH, Comunidades Lhaka Honhat v. Argentina, sentencia del 04 de febrero de 2020, ver párrs. 332-333.

${ }^{98}$ Corte de Justicia de los Estados Africanos del Este, SERAP v Nigeria, ECW/CCJ/APP/08/09 (Sentencia de Fondo, 14 de diciembre de 2012).
} 
Un caso relevante que directamente intenta obligar a un gobierno africano es el de Earthlife Southafrica v. Minister of Environmental Affairs de Sudáfrica. El fundamento del asunto parte de la Convención de la ONU contra el Cambio Climático, el Protocolo de Kyoto y el Acuerdo de Paris. El caso surge en la provincia Limpoo contra una planta de producción de electricidad a base de carbón debido a sus emisiones contaminantes. En la sentencia se reconoció la obligación del gobierno para realizar estudios de impacto ambiental directamente relacionados con el cambio climático y las emisiones de GEI antes de emitir las licencias de la planta ${ }^{99}$.

\section{Tendencias de justicia ambiental y contra el cambio climático en Cortes Constitucionales}

\section{Juliana et al v. United States (2020)}

En los litigios constitucionales que se han desarrollado en varias Cortes se someten a discusión y a una nueva interpretación los derechos de acceso a la justicia ambiental, las cláusulas de igualdad y el deber de protección del Estado, principalmente a favor de grupos en situación de vulnerabilidad y los derechos de las generaciones presentes y futuras.

Juliana et al v. United States ${ }^{100}$ lleva cuatro años (comenzó desde la era Obama) ante la "District Court of Oregon" (DCO) y no ha avanzado lo suficiente debido a los esfuerzos de la administración Trump para frenar la acción civil en contra del gobierno federal. La demanda de Juliana fue incoada por un grupo de niños, niñas y adolescente (NNA) y varias asociaciones civiles que reclaman al gobierno de Estados Unidos, su falta de implementación de planes y mecanismos para disminuir la emisión de GEl y aumentar el calentamiento global. Así, se afirma que varias agencias gubernamentales y el poder ejecutivo de EU

han infringido el derecho de los demandantes a vivir bajo los sistemas naturales vitales de nuestro país, incluido nuestro sistema climático, y su derecho a un sistema climático estable, que son libertades implícitas protegidas de la intrusión gubernamental por la Novena Enmienda ${ }^{101}$.

Como parte de sus argumentos, los demandantes manifiestan que la industria del acero y el carbón y distintas agencias gubernamentales transgreden sus derechos fundamentales que son esenciales en su conjunto: las libertades de propiedad, la protección de sus vidas; de su capacidad de sobrevivir y el derecho a perseguir su felicidad. También se argumenta que este análisis constitucional es histórico y fundamental ya que

las ramas políticas no pueden ejercer su poder a expensas de las libertades en tanto que el poder judicial independiente [...] debe ser el baluarte contra los abusos de otros poderes y hablar por la Constitución y la niñez de América102.

Hasta mayo de 2020, la cuestión de fondo en Julianna v. United States ante la Corte de Apelaciones del Noveno Circuito dilucidaba si los jóvenes promoventes tenían legitimación para pedir un remedio a las violaciones constitucionales de sus derechos o si tendrían que acudir a las vías legislativas y al poder ejecutivo para corregir las omisiones, los actos administrativos y la política ambiental que ponen en riesgo sus derechos y los de las futuras generaciones en Estados Unidos.

\footnotetext{
${ }^{99}$ High Court of South Africa, Earth life Africa Johannesburg v. Minister of Environmental Affairs, case 656216 (Sentencia del 8 de marzo de 2017), párrs. 124-126.

${ }^{100}$ DCO - Eugene Division, First Amended Complaint, Case 6:15-cv-01517-TC, 10 de septiembre de 2015, párrs. 64, 98 y 99.

${ }^{101}$ DCO - Eugene Division, First Amended Complain, Case 6:15-cv-01517-TC, 10 de septiembre de 2015, párrs. 54, 64, 98 y 99. La Novena Enmienda establece que no se pueden negar otros derechos inherentes a las personas a pesar de que esos derechos no estén dentro del texto constitucional.

${ }^{102}$ Supreme Court of the United States (18 de octubre 2018), “№. 18A410 In RE United States”, p. 54.
} 
La acción de tutela en materia de protección a la Amazonia fue interpuesta por menores y adolescentes de Colombia. En la sentencia 360-2018, la Corte Suprema de Justicia de Colombia (CSJC) advirtió los graves riesgos de la deforestación de las selvas colombianas y ordenó la creación de un plan nacional, a largo plazo, para proteger el derecho de las futuras generaciones. Es importante precisar que la acción de tutela fue rechazada en primera instancia pues sigue existiendo el estigma de que no es viable la protección del ambiente a través de los tribunales por no ser el mecanismo idóneo; o, por no acreditar el perjuicio irremediable ${ }^{103}$ por parte de los demandantes, en este caso, un grupo de niñas, niños y adolescentes.

En el fallo definitivo, la CSJC asume que las obligaciones del Acuerdo de París son vinculantes y para demostrar la relación causa-efecto la CSJC hizo hincapié en los informes de la deforestación temprana que sufre la Amazonia al señalar que la "conservación de la Amazonia era una cuestión nacional y global por tratarse del principal eje ambiental del planeta"104. La decisión de la CSJC tuvo por objeto reconocer la región amazónica colombiana como sujeto de derechos por su relevancia y necesidad de conservación, con una perspectiva ecocéntrica compatible con el medio ambiente como derecho colectivo, la salud y la vida digna ${ }^{105}$. El avance significativo de este caso fue la decisión de ordenarle al ejecutivo y legislativo "La elaboración de un plan de acción a corto, mediano y largo plazo denominado Pacto Intergeneracional por la Vida del Amazonas Colombiano (PIVAC)"106. Bajo estas consideraciones, el sistema judicial colombiano está robusteciendo su jurisprudencia ambiental para vincular a sus autoridades a actuar de manera cada vez más eficiente.

Otro caso reciente de Colombia es la resolución de primera instancia en la tutela a favor del Parque los Nevados. La resolución presenta un enfoque integral y coordinado para otorgar especial protección a una zona de importancia biológica y comunitaria. Los hechos que dieron lugar a la demanda interpuesta por NNA pusieron al descubierto las omisiones gubernamentales de cuidado y las actividades tanto públicas como privadas (caza deportiva, extractivismo de minerales y geotermia daños a la flora endémica, tala, erosión, uso indiscriminado de recursos hídricos) que dañan al Parque los Nevados, junto a las amenazas antrópicas y las provenientes del cambio climático ${ }^{107}$. Los razonamientos para proteger de manera integral todo el parque se sustentan en el marco jurídico ambiental internacional ratificado por Colombia en las propias normas y jurisprudencia que han vertebrado su "Constitución Ecológica"108. La portación más relevante de este asunto es la serie de medidas ordenadas en los resolutivos porque se protege el derecho a la vida, a la salud y un ambiente sano; se ordena un plan de recuperación, manejo, mantenimiento y conservación del parque junto con el establecimiento de límites preciso del parque. Finalmente, la sentencia ordena la creación de un mecanismo de supervisión (comité) integrado por todas autoridades competentes y por un panel de expertos ${ }^{109}$.

\section{Urgenda v. Holanda (2019)}

Urgenda es una asociación dedicada al litigio en las Cortes nacionales de Europa para que los gobiernos tomen acciones concretas para reducir el aumento de la temperatura global. En este caso, Urgenda patrocinó a un grupo ambientalista de 900 ciudadanos holandeses quienes demandaron a su gobierno por falta de debida diligencia en la revisión reciente de los objetivos

\footnotetext{
${ }^{103}$ CSJC, “STC 4360-2018”, p. 10.

${ }^{104}$ CSJC, "STC 4360-2018", pp. 25, 34. Entre otros, se fundamenta la Declaración de Río, la Convención de la ONU sobre cambio climático y al Acuerdo de París.

105 CSJC, "STC 4360-2018", p. 49

106 CSJC, "STC 4360-2018", p. 49.

107 Tribunal Superior del Distrito Judicial de Ibagué, Sala Quinta de Decisión Laboral (28 de agosto de 2020), pp. 70-73, 97-104.

108 Tribunal Superior del Distrito Judicial de Ibagué, Sala Quinta de Decisión Laboral (28 de agosto de 2020), pp. 46-64. Se hizo hincapié en la amplia jurisprudencia de la Corte Constitucional Colombiana que ha dado lugar a la Constitución ecológica referida en la T622/16.

${ }^{109}$ Tribunal Superior del Distrito Judicial de Ibagué, Sala Quinta de Decisión Laboral (28 de agosto de 2020), pp. 105-111.
} 
de reducción de emisiones de GEI, pues ello equivalía a una violación del deber de cuidado impuesto y previsto por los artículos 2 y 8 del Convenio Europeo de Derechos Humanos (CEDH).

La Corte de Apelaciones de Holanda concluyó que el Estado tiene el deber de tomar medidas de mitigación del cambio climático debido a la severidad de sus consecuencias y que este siga ocurriendo. Al llegar a esta conclusión, la corte citó las obligaciones positivas del derecho a la vida privada y familiar, vivienda y seguridad jurídica (implícitos en el artículo 8 de la CEDH) que se ven afectados por el calentamiento global ${ }^{110}$. La Corte de apelaciones de Holanda estableció que el gobierno no goza de un margen amplio para no cumplir con las reducciones de proteger los derechos de los artículos 2 y 8 del CEDH en el marco de la certeza de que las actividades industriales son ciertamente una amenaza a la vida de las personas debido a las graves consecuencias de las emisiones de gases de efecto invernadero para el calentamiento global; "la protección efectiva - entonces - requiere que el daño sea prevenido tanto como sea posible por la intervención a tiempo del gobierno ${ }^{111}$. En este sentido, la Corte holandesa estableció que existe un vínculo claramente identificable entre las emisiones antropogénicas de dióxido carbono y el calentamiento global, y por ello el incremento de las temperaturas podrá causar mayores inundaciones, daños a los ecosistemas, largas temporadas de calor, enfermedades respiratorias; catástrofes que enfrentará esta y las generaciones venideras ${ }^{112}$. Hasta ahora, Urgenda $v$. Holanda representa el único caso con un énfasis claro y directo de las obligaciones contraídas por un gobierno (en este caso el de Holanda) para mitigar el cambio climático a través de diversas normas internacionales y regionales que le son vinculantes.

\section{Los casos ambientales en México}

En México los enfoques de la justicia ambiental que arrojan diversas sentencias de amparos contra actos y omisiones de los sectores gubernamentales tienen como nota distintiva la protección de los ecosistemas como proveedores de servicios ambientales ${ }^{113}$; aunque aún no hay fallos sobre el cambio climático en México. Un caso que fijará la ruta de ulteriores litigios es el "Amparo Laguna del Carpintero". Una primera aportación de este caso es que vincula la protección preventiva en relación con el derecho de participación ciudadana (interés legítimo de los vecinos de la zona del manglar) cuando se trata de derechos ambientales afectados por proyectos de infraestructura. La segunda aportación proviene del principio de no regresión, que implica el deber de protección de los ecosistemas por parte de las autoridades de todos los ámbitos; y una tercera es que el amparo otorgado reconoce objetivamente los servicios ambientales que prestan los humedales como parte de los derechos humanos a la salud, y al medio ambiente sano y digno ${ }^{114}$.

El marco jurisprudencial mexicano ofrece varios enfoques sobre la protección ambiental en relación con el derecho a la consulta y el principio de precaución. Mediante ambas directrices se han otorgado diversos amparos a favor de los pueblos indígenas frente a proyectos extractivos y por la siembra de soya transgénica ${ }^{115}$ y también se anuló una ley que autorizaba el incremento de etanol en la gasolina. En este último, se resaltaron las obligaciones estatales para

\footnotetext{
${ }^{110}$ Gerechtshof Den Haag, “Urgenda vs Ministerio de Infraestructura y Medio Ambiente” (Resolución 9 de octubre de 2018), párr. 40.

${ }^{111}$ Gerechtshof Den Haag, "Urgenda vs Ministerio de Infraestructura y Medio Ambiente” (Resolución 9 de octubre de 2018), párr. 44.

${ }^{112}$ Gerechtshof Den Haag, “Urgenda vs Ministerio de Infraestructura y Medio Ambiente”, (Resolución 9 de octubre de 2018), párrs. 44 y 45.

113 Verbigracia, el Amparo 267/2014 para preservar una zona lacustre de gran biodiversidad en la ciudad de México; el Amparo contra infraestructura hotelera en Tajamar y por afectación a los manglares, y el Amparo 307/2016, en el que se reconoció la legitimación activa de un grupo de activistas para impedir la construcción de un parque sobre los manglares de la laguna del carpintero. Véase DE PAZ y MACÍAS (2019), pp. 47-50.

${ }^{114}$ Amparo en revisión 307/2016, 1ra Sala SCJN (14 de noviembre de 2018), párrs. 73, 74, 98-110, 124, 131-134. La obra planeada era un parque de diversiones construido entre el Municipio y la Coca-Cola, grupo Femsa en México.

115 Las sentencias que han martillado estos temas son de los amparos de las "Comunidades Mayas v. Monsanto" ante la SCJN. Ver DE PAZ y MACÍAS (2019), pp. 45, 48.
} 
mejorar la calidad del aire y reducir los efectos de los gases de invernadero que provocan el cambio climático ${ }^{116}$.

\section{Conclusiones}

De la revisión empírica de los casos provenientes de distintas jurisdicciones se puede afirmar que las sentencias han visibilizado y materializado el contenido de las normas de derecho ambiental y muestran tres tendencias de la justicia ambiental para obligar a los gobiernos a:

a) Realizar acciones concretas de protección de zonas de importancia biológica y reducir la contaminación del aire y tierra.

b) Revertir obras de infraestructura que tienen impacto ambiental por la emisión de gases de efecto invernadero para la protección de generaciones presentes y futuras.

c) Ampliar legitimidad de grupos de interés atípicos en el litigio, como niños, niñas y adolescentes para reivindicar sus derechos al amparo de las normas internacionales $y$ constitucionales sobre el ambiente.

Las tres tendencias globales se ubican dentro de la línea evolutiva de la justicia ambiental que parte de las pautas planteadas inicialmente por la $\mathrm{CIJ}$, y que continua mediante los casos ante la CJUE y la Corte IDH sobre la obligatoriedad de la información ambiental y la protección concreta de ecosistemas. Sin embargo, ni la jurisdicción regional europea ni la interamericana han entrado al fondo en el estudio de actos y omisiones que propician el cambio climático.

Hasta ahora, la única sentencia contra la emisión de GEl y el cambio climático ha sido ante una corte nacional, en el caso de Urgenda $v$. Holanda. Este asunto será un referente global para que diversos procesos sometan a controversia los actos y omisiones gubernamentales que provocan un aumento de gases invernadero y propician el cambio climático; y en este sentido, se espera que, de llegar a etapa de sentencia, Juliana $v$ United States produzca un resultado similar al de Urgenda. Las tendencias globales del litigio ambiental muestran una primera etapa para lograr la exigibilidad judicial de las normas ambientales y en razón del alto número de casos en proceso, se augura un incremento de resoluciones que reivindiquen los deberes ambientales de los gobiernos y los obliguen a revertir los efectos que produce el cambio climático. Aunque diversos grupos de litigantes europeos han visto poco éxito en el litigio y optan por otro tipo de estrategias ${ }^{117}$ la realidad muestra que el litigio es una ruta exitosa que genera presión a los gobiernos y a los órganos regionales.

Una cualidad de las sentencias analizadas es que en cada ámbito jurisdiccional se aplica de forma gradual e interconectada la legislación nacional, los principios ambientales de no regresión, precaución, prevención y cooperación y el marco ambiental internacional. Otro rasgo del litigio global es que las rutas procesales difieren en cada jurisdicción. Por ejemplo, la revisión de casos muestra que si bien se combaten mediante procedimientos de queja regionales sustentados en legislación común (como el sistema europeo), también hay acciones civiles sobre daños a los derechos (Juliana) o juicios administrativos (Urgenda), acciones de tutela (Colombia) y de amparo en México. En este sentido, se augura una segunda ola de casos, cada vez con más precisión que pidan medidas jurisdiccionales frente a leyes, omisiones y políticas públicas por su falta de eficacia en la prevención de la contaminación, la pérdida de especies y la reducción de gases de efecto invernadero.

En general, la protección internacional del medio ambiente está tomando fuerza y con ello se amplía la legitimación procesal de grupos para cuestionar de manera autónoma la emisión de GEI para el año 2030, reducir sus actividades industriales de generación de energía y los efectos del cambio climático, tal como se demuestra con las dos peticiones planteadas en 2019: una promovida por los pobladores de la Isla Torres Strait en contra del gobierno de

\footnotetext{
${ }^{116}$ Segunda Sala SCJN, (Sesión del 13 de noviembre de 2019) Amparo en Revisión 619/2019.

${ }^{117}$ HILSON (2019), p. 397.
} 
Australia ante el Comité de Derechos Humanos de la ONU ${ }^{118}$; y una Comunicación de 16 NNA ante el Comité de los Derechos del Niño de la ONU en contra de cinco de los mayores emisores de GEI: Alemania, Francia, Brasil, Argentina y Turquía, en la que los NNA argumentan que el cambio climático constituye una violación a sus derechos de salud, vida, e interés superior (entre otros) ${ }^{119}$. Hasta el mes de agosto de 2020 , ambos procedimientos carecían de análisis de fondo ante los respectivos Comités.

Finalmente, las sentencias y los procesos analizados en este artículo posicionan la actualidad, importancia y autonomía del ambiente como derecho exigible y justiciable. De esta manera, los litigios contra el cambio climático y el daño ambiental reivindican la función judicial y la urgencia de maximizar las directrices y los principios ambientales para hacer efectivas las obligaciones internacionales y nacionales de los Estados en la materia, pero la estrategia de litigio también debe acompañarse de cambios legislativos y -sobre todo- las decisiones judiciales deben impulsar una política pública local, nacional, regional e internacional para que se garantice la continuidad de la vida humana en el planeta.

\section{BIBLIOGRAFÍA CITADA}

Aguilar Cavallo, Gonzalo (2020): “El contenido y los alcances contemporáneos del derecho al acceso a la participación ambiental”, en: Revista lus et Praxis (Vol. 26, № 2), pp. 78-103.

Anglés HeRnÁndez, Marisol (2011): "Fallo de la Corte Internacional de Justicia en materia ambiental, evidenciado en el asunto de plantas de celulosa sobre el río Uruguay", en: Anuario Mexicano de Derecho Internacional (Vol. 11), pp. 77-98.

Arnold, Craig Anthony (1998): "Planning Milagros: Environmental Justice and Land Use Regulation", en: Denver University Law Review (Vol. 76, № 1), pp. 1-153.

BelL-JaMES, JUSTINE (2019): “Integrating the Ecosystem Services Paradigm into Environmental Law: A Mechanism to Protect Mangrove Ecosystems?", en: Journal of Environmental Law (Vol. 31, № 2), pp. 291-31.

BeretTA, ILARIA (2012): "Some Highlights on the Concept of Environmental Justice and its Use", en: e-Cadernos CES (Vol. 15, № 12), pp. 136-162.

BorRas Pentinant, Susana (2013): "La Justicia Climática: Entre la Tutela Y La Fiscalización de las Responsabilidades", En: ANuARIo Mexicano De Derecho InTernacional (Vol. 13), Pp. 3-49.

BULLARD, ROBERT D. Y JOHNSON, GLENN (2000): “Environmental Justice: Grassroots Activism and Its Impact on Public Policy Decision Making", en: Journal of Social Issues (Vol. 56, № 3) pp. 555-578.

Cardoso Neto, Nicolau (2020): "El agua como tema transversal de actuación del derecho ambiental y sanitario en Brasil", en: Revista Mexicana de Derecho Constitucional Cuestiones Constitucionales (№ 42), pp. 137-153.

Carlarne, Cinnamon P.; Gray, KeVIn R. y TARAsofsky, Richard (2016): The Oxford Handbook of International Climate Change Law (Oxford, Oxford University Press).

CLIENTEARTH (2019): "Climate threatened Torres Strait Islanders bring human rights claim against Australia". Disponible en: https://bit.ly/3uc6BdD [visitado el 30 de agosto de 2020].

Danish Ministry Of Climate, Energy and Utilities (2019): "During the COP, Denmark passes Climate Act with a 70 percent reduction target". Disponible en: https://bit.ly/3gVYLRD [visitado el 25 de julio de 2020].

\footnotetext{
${ }^{118}$ CLIENTEARTH (2019).

119 UNITED NATIONS (2019), pp. 27-45, 70-89.
} 
De PAZ GonzÁLEZ, ISAAC (2018): The Social Rights Jurisprudence in the Inter-American Court of human Rights. Shadow and light in international human rights (United Kingdom, Edward Elgar).

De Paz González, IsaAc y Macías Sandoval, María del Refugio (2019): "La justiciabilidad de los derechos sociales. Altibajos de su interpretación constitucional en México", en: Revista Latinoamericana de Derecho Social (№ 29), pp. 25-62.

EDWARDS, VANESSA (2006): "European court of justice-significant environmental cases 2005", en: Journal of Environmental Law (Vol. 18, № 1), pp. 161-168.

ELLIS, C. ERLE (2018): The Antrophocene. A very short introduction (Oxford, Oxford University Press).

FILČÁK, RICHARD (2012): Living Beyond the Pale: Environmental Justice and the Roma Minority (Central European University Press).

Fisher, ElizABeth; LANGe, Bettina y SCOtford, Eloise (2019): Environmental Law: Text, Cases, and Materials, 2a edición (Oxford, Oxford University Press).

Grantham Research Institute On Climate Change And The Environment (2019): "Climate Change Laws of the World". Disponible en: https://climate-laws.org/ [visitado el 30 de agosto de 2020].

Gómez SieRra, Lizeth Del CARMEn Y León OntiVEROS, Ángel (2016): “De los derechos ambientales a los derechos de la naturaleza: racionalidades emancipadoras del derecho ambiental y nuevas narrativas constitucionales en Colombia, Ecuador y Bolivia", en: Misión Jurídica, Revista de Derecho y Ciencias Sociales Bogotá (enero-junio), pp. 233-260.

Government Of IReland (2019): "National Energy and Climate Plan (NECP), 2021-2030". Disponible en: https://bit.ly/3xKgDox [visitado el 30 de agosto de 2020].

GutiérRez Arguedas, Alberto (2014): "En el camino de la justicia ambiental: estableciendo vínculos entre medio ambiente y justicia social”, en: Revista de Ciencias Sociales (№ 146), pp. 113-125.

HAJJAR, LEIB L. (2011): Human Rights and the Environment. Philosophical, Theoretical and Legal Perspectives (Leiden, Martinus Nijhoff Publishers).

HILSON, CHRIS (2019): "Climate Populism, Courts, and Science", en: Journal of Environmental Law (Vol. 31, № 3), pp. 395-398.

JARIA-MANZANO, JORDI (2019): "Los principios del derecho ambiental: Concreciones, insuficiencias y reconstrucción”, en: Revista lus et Praxis (Vol. 25, № 2), pp. 403-432.

KLEIN, NAOMI (2015): Esto lo cambia Todo. El Capitalismo contra el clima (México, Planeta).

LuCero PANTOJA, JaIRo EnRIQue (2015): “Pasteras, un trabajo que obvió el progreso: un análisis propositivo desde la crítica constructiva", en: Revista Científica CODEX (Vol. 1, № 1), pp. 53-76.

Milkoreit, Manjana (2019): "The Paris Agreement on Climate Change-Made in USA?", en: Perspectives on Politics (Vol. 4, № 17), pp. 1019-1037.

Olivares, Alberto y Lucero, Jairo (2018): “Contenido y desarrollo del principio in dubio pro natura”, en: Revista lus et Praxis (Vol. 24, № 3), pp. 619-650.

PAVONI, RICCARDO (2013): "Environmental Jurisprudence of the European and Inter-American Courts of Human Rights Comparative Insights", en: Boer, Ben (Ed.), The Environmental Dimension of Human Rights (Oxford, Oxford University Press), pp. 69-106.

Sabine Center For Climate Change law (2020): “Climate Change Litigation Databases". Disponible en: http://climatecasechart.com [visitado el 30 de agosto de 2020]. 
SCRANTON, ROYNE (2015): Learning to Die in the Anthropocene: Reflections on the End of a Civilization (San Francisco, City Lights Books).

SIMON CAMPAÑA, FARITH (2013): "Derechos de la naturaleza: ¿innovación trascendental, retórica jurídica o proyecto político?", en: luris Dictio (Vol. 13, № 15), pp. 9-38.

SteINAR, ANDRESEN (2016): "The Role of International Courts and Tribunals in Global Environmental Governance", en: ASPJ Africa \& Francophonie (3rd Quarter), pp. 67-81.

StePHENS, TIM (2009): International Courts and Environmental Protection (Cambridge, Cambridge University Press).

The Center For International Environmental Law (2013): "Climate Change and Human Rights. A Primer". Disponible en: https://bit.ly/3nJ07Rb [visitado el 30 de agosto de 2020].

THORNTON, JAMES Y GOODMAN, MARTIN (2018): Client Earth (London, Scribe).

United Nations (2019) "Communication to the Committee on the Rights of the Child, Chiara Sachi et al v. Argentina, Brazil, France Germany \& Turkey (23 de septiembre de 2019)". Disponible en: https://bit.ly/3eXqZce [visitado el 30 de agosto de 2020].

VAN RIJSWICK, H.F.M.W. Y BACKES, CHRIS W. (2015): “Ground Breaking Landmark Case on Environmental Quality Standards?", en: Journal for European Environmental \& Planning Law (Vol. 12), pp. 363-377.

WHITE, ROB (2014/2015): "Indigenous communities, environmental protection and restorative justice”, en: Australian Indigenous Law Review (Vol. 18, № 2), pp. 43-54.

\section{JURISPRUDENCIA CITADA}

ONU, Trail smelter case-United States, Canada (16 de abril 1938 y 11 de marzo de 1941).

CORTE INTERNACIONAL DE JUSTICIA:

CORTE INTERnACIONAL DE JustiCIA, "Nuclear Tests Case (New Zealand v. France" (Sentencia del 20 de diciembre de 1974).

CORTE INTERNACIONAL DE JUSTICIA, “Opinión Consultiva sobre la legalidad de las armas nucleares" (8 de julio de 1996).

CORTE INTERNACIONAL DE JUSTICIA, "Proyecto Gabcikovo-Nagymaros, Hungría v Eslovaquia" (Sentencia del 25 de septiembre de1997).

CORTE INTERNACIONAL DE JUSTICIA, "Pulp Mills on the River Uruguay (Argentina vs. Uruguay)" (Sentencia del 20 de abril de 2010).

CORTE INTERNACIONAL DE JUSTICIA, “Australia vs. Japón: New Zealand intervening" (Sentencia del 31de marzo de 2014).

CORTE DE JUSTICIA DE LA UNIÓN EUROPEA:

CORTE DE JUSTICIA DE LA UNIÓN EUROPEA, Caso C-404/13, "ClientEarth v. The Secretary of State for the Environment, Food and Rural Affairs" (Sentencia del 19 de noviembre de 2014).

CORTE dE JUSTICIA DE LA UNIÓN EUROPEA, Caso C-461/13, "Bund für Umwelt und Naturschutz Deutschland e.V. contra Bundesrepublik Deutschland", Gran Sala (Sentencia del 1 de julio de 2015).

CORTE DE JUSTICIA DE LA UNIÓN EUROPEA, Caso C-387/15 y C-388/15 acumulados, "Hilde Orleans and Others v Vlaams Gewest" Sala Séptima (Sentencia del 21 de julio de 2016). 
CORTE DE JUSTICIA DE LA UnIÓN EUROPEA, Caso C-142/16, “Comisión Europea v. República Federal de Alemania", (Sentencia del 26 de abril de 2017).

CORTE de JustiCia de LA Unión EuRopea, Caso C-441/17, "Commission v. Poland", (Sentencia 17 de abril de 2018).

CORTE DE JUSTICIA DE LA UNIÓN EUROPEA, Caso C-164/17, “Inter-Environnement Wallonie ASBL, Bond Beter Leefmilieu Vlaanderen ASBL v. Conseil des ministres con intervención de Electrabel SA Gran Sala", (Sentencia del 25 de julio de 2018).

CORTE DE JUSTICIA DE LA UnIÓN EUROPEA, Caso C-57/16, Gran Sala, “ClientEarth v. Comisión Europea” (Sentencia del 4 de septiembre de 2018).

CORTE DE JUSTICIA DE LA UnIÓN EUROPEA, Caso C-565/19 P, "Carvalho and Others v. Parliment and Council", Segunda Sala (Orden del 8 de mayo de 2019).

CORTE INTERAMERICANA DE DERECHOS HUMANOS:

Corte Interamericana de Derechos Humanos, Claude Reyes y otros v. Chile, Sentencia de 19 de septiembre de 2006 (Fondo, Reparaciones y Costas) Serie C. 151.

Corte Interamericana de Derechos Humanos, Kawas Fernández V. Honduras, Sentencia de 3 de abril de 2009 (Fondo, Reparaciones y Costas) Serie C. 196.

CORTE INTERAMERICANA DE DERECHOS HuMANOS, Opinión Consultiva OC-23-17, Resolución de 15 de noviembre de 2017, Serie A. 23.

CORTE INTERAMERICANA DE DERECHOS HUMANOS, Comunidades Indígenas miembros de la asociación Lhaka Honhat v. Argentina, Sentencia de 6 de febrero de 2020 (Fondo, Reparaciones y Costas) Serie C. 400.

\section{CORTES NACIONALES:}

Corte de Justicia de los Estados Africanos del Este, SERAP (Socio-Economic Rights and Accountability Project) v Nigeria, ECW/CCJ/APP/08/09, Sentencia de Fondo, 14 de diciembre de 2012.

District Court District of OREgON - EUgene Division, "Julianna v. United States", First Amended Complaint, Case 6:15-cv-01517-TC, 10 de septiembre de 2015.

HIGH COURT OF SOUTH AFRICA, Earth life Africa Johannesburg v. Minister of Environmental Affairs, case 656216 (Sentencia del 8 de marzo de 2017).

Corte SupRema de Justicia de Colombia, STC 4360-2018, Sentencia del 5 de abril de 2018.

SUPREME CouRT OF THE UNITED STATES №. 18A410 In RE United States, et al, Resolución de fecha 20 de julio de 2018.

GeRECHTSHOF DeN HAAG, Caso C/09/456689/HA ZA 13-1396, Urgenda vs Ministerio de Infraestructura y Medio Ambiente de Holanda (Resolución de 9 de octubre de 2018).

SCJN DE MÉXICO, Amparo en revision 307/2016, 1a Sala (Sentencia de 14 de noviembre de 2018). SCJN DE MÉXICO, 2a Sala Amparo en Revisión 619/2019 (Sesión del 13 de noviembre de 2019).

Tribunal SUPERIOR del Distrito JUdiCIAL de Ibagué, Sala Quinta de Decisión Laboral (Colombia), Sentencia del 28 de agosto de 2020. 